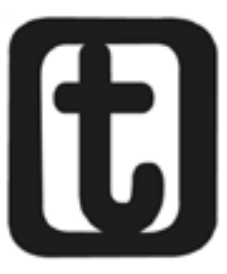

\title{
A PÓS-GRADUAÇÃO EM SERVIÇO SOCIAL NO BRASIL: UM PATRIMÔNIO A SER PRESERVADO
}

\author{
Postgraduate program in Social Work in Brazil: \\ heritage to be preserved
}

Yolanda D. Guerra'

Para Nobuco Kameyama Pelo patrimônio legado à pós-graduação e à pesquisa

A ciência não é algo que se recebe, mas sim algo que se desenvolve, algo cujo sangue espiritual se impulsiona do coração até as extremidades (HEGEL apud ENDERLE, 2006, p. 12).

\section{RESUMO}

Neste artigo, escrito no ano em que a ABEPSS completa seus 65 anos, menos do que celebrar a data, pretende-se analisar criticamente a trajetória da pós-graduação em Serviço Social no Brasil, situando-a nas configurações da Política Nacional de Pós-Graduação, refletindo sobre a sua relevância no âmbito das ciências sociais aplicadas e na afirmação do projeto ético-político profissional, bem como sobre seus dilemas e desafios. Parte da premissa de que os desafios e possibilidades da pós-graduação em Serviço Social só podem ser apreendidos no movimento histórico de avanços e retrocessos da política educacional brasileira e, em especial,

'Assistente social, mestre e doutora em Serviço Social pela PUC-SP, Professora da Escola de Serviço Social da Universidade Federal do Rio de Janeiro, Membro da Comissão Editorial da Temporalis. E-mail: <yguerra1@terra.com.br>. 
nas orientações desta para a pós-graduação. Argumenta-se que a pós-graduação cumpriu um papel de monta na constituição da vertente crítica do Serviço Social brasileiro, que hoje detém hegemonia na produção do conhecimento e da pesquisa, responsável pela renovação da imagem profissional e por tornar o Serviço Social contemporâneo de seu tempo, colocando-o como interlocutor reconhecido no campo das ciências sociais.

\section{PALAVRA-CHAVE}

Pós-graduação - Avanços, retrocessos, dilemas, possibilidades.

\section{ABSTRACT}

This article written in the year of ABEPSS' 65th anniversary aims not only at celebrating this date, but also critically analyzing the history of social work postgraduate programs in Brazil. It lies on Brazilian Postgraduate Policy setting, reflecting on its relevance to the field of social sciences. This study departs from the premise that the challenges and possibilities of postgraduate programs in social work can only be apprehended in the historical advances and back moves of Brazilian educational policy, especially in its guidelines to postgraduate programs. We advocate that postgraduate programs played a significant role in the constitution of the critical current of Brazilian social work, which holds hegemony in knowledge production and research; promotes a new image of social work professionals; makes social work a contemporary science; and places social work as an accredited interlocutor in the field of social sciences.

\section{KEYWORDS}

Postgraduate program; advances, retrogression, dilemmas, possibilities. 


\section{INTRODUÇÃO}

Comemorando uma trajetória de fecundas realizações, a Associação Brasileira de Ensino e Pesquisa em Serviço Social vem investindo - sobretudo nos últimos 15 dos seus 65 anos - na consolidação da Pós-Graduação da área de Serviço Social.

Criada desde 1946 como ABAS, vigorando por anos como ABESS, a atual ABEPSS explicita desde a sua nomenclatura que tem como princípio e compromisso a relação orgânica entre graduação e pós-graduação, por entender que na consolidação da pós-graduação localizam-se as condições para a qualificação da graduação. Assim, a pós-graduação aporta contributos teórico-metodológicos à graduação que, por sua vez, requalificada, torna-se insumo do desenvolvimento da pós-graduação.

A mudança estatutária operada em 1998, que integra o Centro de Documentação e Pesquisa em Política Social e Serviço Social (CEDEPSS) à $A B E S S$, nominada a partir daí como ABEPSS, foi a forma de dar amparo jurídico-legal a uma concepção que vinha sendo construída coletivamente: a relação orgânica entre graduação e pós-graduação e a indissociabilidade do tripé ensino, pesquisa e extensão como eixo que estrutura a formação profissional graduada e pós-graduada, se constituindo em condição para consolidar a formação e a produção do conhecimento. Com ela, a nascente ABEPSS passa a ter legitimidade como entidade acadêmico-científica e política.

Tal mudança nem de longe se restringia à sua denominação: ela expressava o grau e o nível de maturidade que a pesquisa na área havia alcançado e a necessidade de socializar o conhecimento produzido. Com este artigo, menos do que proceder a um resgate histórico da pós-graduação no Brasil, pretende-se captar, no contexto da sua historicidade, a lógica que tece, sustenta e orienta a sua existência, particularizando-a no Serviço Social.

A premissa é a de os desafios e possibilidades da pós-graduação em Serviço Social só podem ser apreendidos no movimento histórico de avanços e retrocessos da política educacional brasileira e, em especial, nas orientações desta para a pós-graduação. 
Nesta direção, cabe-nos indicar, como o fazem alguns estudiosos sobre o tema, que, embora as origens da Pós-Graduação no Brasil possam ser identificadas a partir da década de 1930 do século passado, é na década de 1960 - através do parecer da Câmara de Ensino Superior, $n^{\circ}$ 977/65, conhecido como parecer Sucupira, aprovado pelo Conselho Federal de Educação, sob a égide do regime militar - que a pós-graduação no Brasil se institucionaliza como um sistema.

São as transformações econômicas, políticas, sociais e culturais da década de 1960, as novas e antigas determinações que caracterizam a expansão do capitalismo mundial que estabelece uma determinada relação excludente e subordinada em relação aos países da América Latina, o solo histórico sobre o qual ela se ergue e a lógica que a justifica.

Naquela conjuntura, fazia-se necessário assegurar determinado tipo de pesquisa e de produção tecnológica e cientifica que viessem a dar suporte ao projeto de transformação capitalista instaurado pela ditadura, caracterizado pela aceleração econômica, dependência do capital externo e por uma dinâmica que garantia, mas também restringia, o acesso aos bens e serviços apenas aos segmentos da classe burguesa, dando prosseguimento à histórica herança de exclusão da massa da população brasileira.

A lógica da sua implantação era parte constitutiva do projeto de modernização conservadora e tinha por objetivo a consagrada integração entre centro e periferia, o que evidencia claramente nosso processo de dependência. Essa integração implicava a expansão de mercados consumidores nos países periféricos e o fomento aos países centrais enquanto produtores de Ciência e Tecnologia. É importante lembrar que o objetivo das nações mais desenvolvidas era o aumento de mercados consumidores e o desestímulo à concorrência científica ou tecnológica².

\footnotetext{
${ }^{2}$ A interferência da United States Agency for International Development (Usaid) nos rumos da educação brasileira na década de 1960 deve ser entendida sob esta ótica.
} 
Foi neste contexto de dependência em relação às nações centrais que se deu a instalação da pós-graduação no Brasil'.

Pondo fim às aspirações nacional-populistas, o projeto da ditadura, no intuito de constituir uma sociedade urbano-industrial na periferia do capitalismo mundial, tinha na educação a sua estratégia principal. Esta era fundada na racionalidade técnica do que decorrem a substituição dos políticos pelos tecnocratas, a garantia da relação orgânica entre educação e aumento da produtividade da economia nacional e a ampliação de vagas em cursos tecnológicos. Para o alcance destes objetivos, o desenvolvimento da pós-graduação (que, como vimos, tem sua implantação desde a década de 1930) se constituía em estratégia das mais eficazes.

A expansão da pós-graduação no Brasil neste período cumpre ainda uma função de monta: a perspectiva de configurar à universidade um determinado perfil de neutralidade, assepsia, tecnocratismo, conformando e sustentando uma racionalidade formal-burocratica. Internamente, foi necessário que a ditadura promovesse um projeto que vele, acoberte, dissimule sua natureza coercitiva. $O$ invólucro mistificador de que ele se recobre tanto se faz pela ideologia tecnicista quanto ganha corpo na constituição de uma tecnoburocracia.

É importante ressaltar que a criação da pós-graduação no Brasil obedece à mesma lógica de tantos outros processos históricos do Brasil e de outros países da América Latina: foi criada pelo alto, para atender aos interesses de uma burguesia nacional e, sobretudo, estrangeira. Não é casual que ela adota um formato elitista e serve para constituir o que Netto (1990) denomina mandarinato acadêmico.

A partir dos acordos conhecidos como MEC-Usaid (conforme nota 1), o formato da pós-graduação no Brasil passa a ser organizado nos moldes da filosofia e estrutura dos EUA, os quais privilegiam: a formação de professores que atenda a pretensão de expandir o

${ }^{3}$ Através do Parecer 977/1965 exarado pela Câmara de Ensino, de autoria de Nelson Sucupira, dá-se a implantação formal dos cursos de pós-graduação no Brasil. 
ensino e o estimulo à pesquisa voltada para atender estritamente os interesses do mercado; o treinamento de técnicos vislumbrando as necessidades do desenvolvimento nacional naqueles setores privilegiados pela ditadura, bem nos moldes da Teoria do Capital Humano, desenvolvida por Teodore Schultz ${ }^{4}$. Neste modelo, há um inequívoco interesse no investimento na formação de gerentes e técnicos, capazes de aplicarem um know-how importado.

O modelo MEC-Usaid mantém a condição de dependência do Brasil por outros países, revelando que a heteronomia da pós-graduação e da própria universidade em face do Estado e dos interesses do mercado faz parte da sua tradição, tendência que nos dias de hoje apenas se acirra e se complexifica.

É importante destacar que grande parte dos pesquisadores do tema considera que a pós-graduação no Brasil participa das estratégias de qualificar profissionais em dois níveis: 1) para atuarem nos projetos de desenvolvimento nacional; 2) para atuarem no ensino superior, dada a necessidade de qualificar o corpo docente. Tendo em vista estes interesses, Sguissardi (2009, p. 144), apoiado em Hamburger, afirma que a pós-graduação, inspirada no modelo norte-americano "[...] se viu patrocinada em suas origens, por dois setores da tecnocracia governamental: o da área econômica e o da área educacional". Tal modelo, claramente recomendado pelo citado parecer 977, funda um sistema de pós-graduação financiado por órgãos como o BNDE, CNPq, Finep e Capes, que, não casualmente à época, se chamava Campanha de Aperfeiçoamento de Pessoal para o Ensino Superior, patrocínio que expressa exatamente seus objetivos e compromissos (HAMBURGER apud SGUISSARDI, 2009, p. 144).

\footnotetext{
4 É no mínimo curioso o fato de que os argumentos dos segmentos do governo para justificar a depreciação do ensino superior no Brasil seguem sendo até hoje, basicamente, os mesmos desde o período da ditadura militar. São eles: necessidade de democratização do ensino (leia-se massificação) e o enfrentamento do baixo índice de matrículas, da suposta rigidez e anacronismo da estrutura curricular, da existência de vagas ociosas, de cursos para os quais não havia demanda de mão de obra, dentre outros. Esta claro que o que há em comum com as condições atuais é o fato de que este projeto tende a precarizar as condições nas quais a educação superior está inserida.
} 
É na década de 70 do século passado, contexto que Florestan Fernandes nomeou como contrarrevolução preventiva5, o período em que este modelo de pós-graduação ganha corpo e se expande.

É também neste contexto e conjuntura, no marco do projeto e do processo de modernização conservadora, tendo em vista a necessidade de desenvolver as forças produtivas e de construir um perfil de profissional que lhe fosse funcional, que se dá a criação da pós-graduação em Serviço Social no Brasil, com claro perfil tecnológico e parametrizada pelo modelo norte-americano, sendo os primeiros cursos implantados nas Universidades Católicas de São Paulo e do Rio de Janeiro, ambos em $1972^{6}$.

Não obstante a esta tendência de continuidade com o modelo alienígena - mas vindo em sentido contrário, como parte de um movimento iniciado em meados da década de 60 que questiona as influências estrangeiras no Serviço Social latino-americano e o tradicionalismo das suas formulações teórico-metodológicas e ético-políticas -, tem-se no ano de 1975 a fundação do primeiro Curso de Pós-Graduação Latinoamericano de Trabajo Social (PLATS) na Universidade Nacional de Honduras, resultado da articulação entre Universidades Centro-Americanas e o Centro de Estudios Latinoamericano de Trabajo Social (CELATS)7. É no contexto do movimento de reconceituação latino-americano, como marco questionador

\footnotetext{
${ }^{5}$ O golpe de 64, segundo Netto (1990), para as “[...] massas trabalhadoras brasileiras [...]", suprimiu um processo de democratização em curso na sociedade brasileira que portava a tendência de operar modificações econômico-sociais profundas, as quais levariam à ruptura com a nossa histórica heteronomia econômica. Este autor denuncia as implicações que o golpe teve para a esquerda brasileira. ${ }^{6}$ Este foi " [...] o primeiro a ser oficialmente credenciado pelo Conselho Federal de Educação (Parecer 4.428/76) - voltado, sobretudo, para a formação de docentes e pesquisadores. Seu objetivo era o de capacitar para a análise crítica da realidade social e para o desenvolvimento de estratégias de intervenção do Serviço Social" (PONTIFICIA UNIVERSIDADE CATÓLICA DO RIO DE JANEIRO, O19922011). É importante lembrar que somente na década de 70, a formação profissional dos assistentes sociais brasileiros deixa os espaços das escolas isoladas para se integrar nos espaços universitários. 7 Cabe notar que como parte de sua política de capacitação continuada, o Centro de Estudios Latino-Americano de Trabajo Social (CELATS), de meados da década de 70 até o final dos anos 80 do século passado, investe na formação em docência destinada aos profissionais e implementa um amplo projeto que pretende o desenvolvimento de pesquisas, a organização da categoria e a capacitação de quadros, visando a formação de uma massa crítica. Em articulação com cientistas políticos, sociólogos e educadores, a referida entidade investe na produção de conhecimento sobre a contemporaneidade (parte dele registrado na Revista Acción Critica) e realiza pesquisas sobre as condições do exercício profissional, a trajetória histórica da profissão, a organização política da categoria e a dinâmica das classes sociais. A este respeito consultar Lima ([1984]).
} 
do conservadorismo profissional e das influências estrangeiras no Serviço Social latino-americano, que se estabelecem as bases para uma interlocução com as ciências sociais. Este movimento questionador da suposta subalternidade profissional e do significado social da profissão desencadeia preocupação com a qualificação profissional e com a pesquisa.

Não é demais lembrar que é a batalha travada contra o tradicionalismo (teórico-metodológico, ético-poltico e prático-profissional) do Serviço Social que o direciona para a sua qualificação, já que esta é pressuposto daquela.

No Brasil, com a inserção da profissão nos circuito acadêmico e a criação das pós-graduações surge um tipo de produção teórica que questiona antigos paradigmas tais como: o Serviço Social como ramo do saber, a existência de objeto e método próprios, o endogenismo, a suposta neutralidade e assepsia dos conhecimentos/ procedimentos técnicos.

Para além do seu papel de formar a massa crítica da profissão, sem dúvida que os recém-criados cursos de pós-graduação na década de 70 do século passado exercem papel fundamental no que se refere a proporcionar a articulação política de um importante segmento da categoria (composto por uma vanguarda, muitos destes sujeitos também dirigentes das entidades à época) que, para qualificar sua atuação política, passa a exigir uma apropriação das matrizes clássicas do conhecimento e o estabelecimento do diálogo com outras áreas de produção do conhecimento ${ }^{8}$.

É no contexto dos anos 80, com o protagonismo da classe trabalhadora e a reascensão dos movimentos sociais e sindicais, que novas exigências teórico-práticas são demandadas à profissão requisitando-Ihe análises e posturas cada vez mais críticas e radicais. A partir daí, passam a ser exigidos aportes teóricos que capacitassem os assistentes sociais para a interlocução com outras áreas de produção

\footnotetext{
${ }^{8}$ A virada do Serviço Social brasileiro, tecida neste fecundo contexto, não se explica sem estas articulações, conquistas e acontecimentos. Ela se nutre especialmente das possibilidades criadas pelos mestrados em Serviço Social que são implantados em todo o pais, a saber: PUC- SP e PUC-RJ em 1972, como já mencionado, UFRJ, em 1976; PUC-RS, em 1977; UFPB-JP, em 1978; e UFPE, em 1979.
} 
do conhecimento, marcando o que lamamoto (1996, p. 90) chamou de "[...] travessia para a maioridade intelectual e profissional dos assistentes sociais, para a sua cidadania acadêmico-política”.

Neste contexto, também a pós-graduação se vê obrigada a se renovar. Este processo é marcado pelo retorno de quadros intelectuais da clandestinidade e do exílio, enriquecendo os programas de pós-graduação e trazendo um pensamento profundamente critico ${ }^{9}$.

Ressalta-se que na década de 80 processa-se na profissão uma importante revisão da formação profissional, com a adoção de novo currículo que opera uma inflexão no perfil de profissional tecnocrata, cuja intervenção se fazia através de métodos de caso individual, grupos e comunidade, com o que se desencadeia um processo de construção de uma cultura crítica, tendo na pesquisa ${ }^{10}$, o seu fundamento, e na produção do conhecimento inovador e contribuição com outras áreas do conhecimento, a sua expressão.

Como resultado de avanços internos e externos da profissão, consolida-se um amadurecimento teórico expresso na conformação de uma massa crítica. Somente a partir daí estão dadas as possibilidades de o Serviço Social investir na busca das bases ontológicas de sua fundação, do que resultou na constituição de uma "nova intelectualidade" (NETTO, 1996), segmento que atua no âmbito da formação, da pesquisa e da produção do conhecimento ${ }^{11}$.

Novo impulso ganha a pesquisa com a implementação do Centro de Documentação e Pesquisa em Política Social e Serviço Social (Cedepss), órgão acadêmico da Abess no ano de 1987, que vige até o ano de 1998, quando da revisão do estatuto da entidade. O Cedepss se constituiu numa estratégia das mais acertadas na ruptura com a endogenia da nossa produção científica e da criação de vín-

\footnotetext{
9 Faltam estudos que nos permitam dimensionar o impacto causado nos nossos programas de pós-graduação com a inserção de intelectuais do porte de Florestan Fernandes, Octavio lanni, dentre outros. No âmbito particular da profissão, o retorno de intelectuais como José Paulo Netto, Marilda lamamoto, Nobuco Kameyama (a quem dedicamos este artigo), Vicente Faleiros, dentre outros, promovem uma inflexão na produção dos programas e no conhecimento que ali é socializado.

${ }^{10}$ É no currículo de 1982 que a pesquisa passa a ser disciplina obrigatória na formação profissional.

"É importante enfatizar o papel da pós-graduação no que se refere a diminuir a distancia entre as produções teóricas e a realidade vivenciada pelos assistentes sociais, para o que a pesquisa se constitui como uma mediação imprescindível.
} 
culos com pesquisadores de áreas afins na construção da pesquisa interdisciplinar. Este período é marcado por fecundas produções e debates especialmente sobre realidade brasileira, polêmica metodológica, crise de paradigmas nas ciências sociais e humanas e suas implicações no conhecimento e na intervenção profissional, configuração de um projeto profissional.

Parte desta produção é inscrita nos Cadernos Abess $^{12}$ e nos Cadernos de Pesquisa do Cedepss ${ }^{13}$, importantes registros da produção do Serviço Social à época.

O Editorial dos Cadernos Abess numero 8, de 1998, marco da transição da entidade, que porta a nova concepção de pesquisa como transversal à formação de graduação e pós-graduação e consolida o tripé ensino, pesquisa e extensão, como já indicado, reflete o espírito da época:

Criando um novo veículo de divulgação inscrito num projeto editorial mais moderno e ágil, que venha a favorecer maior penetração da produção de conhecimento em Serviço Social nos meios acadêmicos da nossa profissão e fora dela, inclusive em âmbito nacional e internacional. Para isso deve redefinir seu projeto (objetivos, periodicidade, conselhos editorais etc) buscando estar compatível com as exigências e desafios que se colocam à nova entidade (EDITORIAL, 1998).

Sobre a fecundidade do período marcado pela passagem dos anos 70 para os anos 80 do século $\mathrm{XX}$, período no qual se opera uma profunda renovação do Serviço Social brasileiro, Netto (2005) considera que:

Integrado no sistema universitário em todos os níveis (graduação e pós-graduação), nos anos oitenta

\footnotetext{
${ }^{12}$ Esta produção vigorou entre os anos de 1986 a 1998 quando foi substituída pela Revista Temporalis.

${ }^{13}$ Os Cadernos de Pesquisa Cedepss, nos seus dois números inaugurais, trataram de um tema de extrema relevância para a profissão: a configuração de um projeto profissional para o Serviço Social. No numero 1, abordou $O$ pensamento das entidades nacionais; no número 2, apresentou o "[...] estudo de 10 anos da Revista Serviço Social e Sociedade (1979-1989)" - ambos organizados sob a coordenação da profa. Maria Ozanira Silva Silva (Cf. Abess - Cedepss, ago. 1994).
} 
o Serviço Social brasileiro assistiu ao desenvolvimento de uma perspectiva crítica, tanto teórica quanto prática, que se constituía a partir do espírito próprio da Reconceituação. Não se tratou de uma simples continuidade das idéias reconceitualizadoras, uma vez que as condições históricas, políticas e institucionais eram muito diversas das do período anterior; antes, o que se operou foi uma retomada da crítica ao tradicionalismo a partir das conquistas da Reconceituação - por isso, é adequado caracterizar o desenvolvimento deste "Serviço Social crítico" no Brasil como herdeiro do espírito da Reconceituação: comprometido com os interesses da massa da população, preocupado com a qualidade acadêmica e com a interlocução com as ciências sociais e investindo fortemente na investigação (NETTO, 2005 p.82).

Por meio de uma vertente crítica, o Serviço Social brasileiro consolida a sua maturidade intelectual (NETTO, 1996; IAMAMOTO, 1992), alcança o reconhecimento e a validação acadêmica como área de produção de conhecimento, determina seu estatuto profissional e o seu significado social, contribui na consolidação das Ciências Sociais no Brasil, adquire visibilidade no campo acadêmico e investe na construção de um projeto de sociedade que defende a educação laica, pública, gratuita, democrática, socialmente relevante e autônoma em face dos constrangimentos da racionalidade burguesa.

Também se destaca o papel que joga a constituição da pós-graduação na difusão da tradição marxista e do pensamento marxiano no que se refere a imprimir a preocupação com a busca dos fundamentos e do questionamento da visão tecnicista e instrumental da profissão.

\section{Conforme considera Netto (apud lamamoto, 1992, p.9-19):}

A mais ampla e profunda renovação que o Serviço Social vinha experimentando no Brasil, do ponto de vista da sua auto-representação, nos últimos vinte anos, ganhou ritmo e significado inéditos a partir de finais da década de 70 [...]. Trata-se de um giro notável, cuja evidência mais perceptível é a interlocução com a tradição marxista. Sem prejuízo das mo- 
dificações que já estavam em andamento, apelando a matrizes teóricas outras, é a interlocução com o pensamento marxista que confere ao Serviço Social no Brasil a sua carta de cidadania intelectual (NETTO apud IAMAMOTO, 1992, p. 9-19).

Pouco se tem investido em pesquisas que abordem a contribuição da pós-graduação para a renovação do Serviço Social brasileiro. Sabemos que o pensamento crítico entra no Serviço Social, se não exclusivamente, pelo menos, predominantemente, através dos programas de Pós. Esta tendência do pensamento, ao provocar o questionamento do modelo norte-americano, desencadeia um processo de renovação também no interior mesmo dos Programas que, através da produção da pesquisa crítica e engajada, contribui para dar uma fundamentação mais rigorosa à graduação em Serviço Social.

Em 1984, ainda, o Serviço Social obteve reconhecimento pelo Conselho Nacional de Desenvolvimento Científico e Tecnológico (CNPq) como uma área específica de Pesquisa ${ }^{14}$, fato de extrema relevância para fazer fecundar a pesquisa na área.

Não obstante aos avanços sinalizados, como decorrência das contradições próprias da sociedade capitalista, a onda neoconservadora que avança a partir dos finais da década de 80, no Brasil, ameaça, mais uma vez, as tendências de fundar na razão a constituição dos processos e sua explicação, invadindo o Serviço Social e potencializando os vetores mais conservadores e regressivos da nossa cultura profissional. Esta perspectiva tende a defender ora a destruição total da razão, ora o seu amplo empobrecimento. A negação da razão se reveste do debate sobre a crise de paradigmas, fundado na suposição de que as teorias macroscópicas já não dão conta de explicar as transformações contemporâneas, levando ao questionamento da produção teórica pautada nos modelos de cientificidade da modernidade.

${ }^{14}$ Com as seguintes linhas de investigação: Fundamentos do Serviço Social, Serviço Social Aplicado (que mais recentemente se torna Serviço Social do Trabalho), Serviço Social da Educação, Serviço Social do Menor, Serviço Social da Saúde, Serviço Social da Habitação, conforme site do CNPq. 
Por se basear numa concepção de ciência que recusa a busca da universalidade, ela, nos termos de Lukács (1988, p. 103) “[...] se reduz a sustentar a práxis no nível do imediato (e -YG) a sua atividade se transforma em uma manipulação dos fatos que interessam aos homens na prática [...]”, vindo ao encontro do modelo de reestruturação produtiva que atende às necessidades imediatas do mercado e do capitalismo contemporâneo .

\section{A PÓS GRADUAÇÃO NÃO É MAIS AQUELA...}

Apesar dos elementos de continuidade entre o atual projeto de pós-graduação no Brasil e aquele dos anos da sua criação, especialmente no que se refere aos interesses do capital, os anos 2000 consolidam um processo de sucateamento do ensino em todos os níveis reverberando na Pós-Graduação, o que põe em risco o seu padrão de qualidade acadêmica, que, contraditoriamente, marcou o projeto educacional da ditadura ${ }^{15}$.

A flexibilização demandada pelos processos de enfrentamento da crise do capital adentra os espaços do ensino superior no Brasil, no que se refere à sua desregulamentação, flexibilizando a estrutura curricular, de um lado, e estabelecendo um novo marco regulatório $^{16}$, de outro, o qual oferece as bases jurídico-legais para atender as necessidades de valorização do capital no seu atual estágio de desenvolvimento. Na sequência desse desmonte, têm-se os processos de desprofissionalização, com a criação de novas áreas de conhecimento ${ }^{17}$.

\footnotetext{
15 Não é este o lugar, tampouco detenho esta competência, para realizar uma análise da devastação resultante do acordo de Bolonha, mas sabe-se que esta contrarreforma na educação foi resultado do Protocolo assinado por 29 países europeus, no ano de 1999, para padronizar o ensino superior nestes países e trazer mudanças significativas no mundo todo, no que se refere à redução do tempo de formação e titulação e à constituição de um perfil de trabalhador funcional às demandas do mercado.

${ }^{16}$ Identificamos desde a legislação criada para garantir o funcionamento dos cursos a Distância, passando pela legislação que trata do mestrado profissional e culminando com a Lei de Inovação Tecnológica e Lei do Bem, que garante a formação de recursos humanos para as empresas através da vinculação orgânica entre interesses do processo produtivo e a política de pós-graduação.

${ }^{17}$ Neste contexto, surge a Pós-Graduação em Ciências Humanas e Sociais, os Mestrados (em geral, profissionais) nas áreas de Defesa Social, Mediação de Conflitos, Aconselhamento Familiar, Direito Social, Vegetarianismo, Enfermidades e Doutorados em Teorias da Justiça e Teorias da sociedade, dentre outros. Dentro desta lógica também surgem os mestrados multiprofissionais e as atuais demandas para as políticas setoriais, a exemplo dos Mestrados Profissionais na Saúde ou em Saúde da Família.
} 
A compressão espaço-tempo, marca da nossa contemporaneidade, o movimento do capital na direção da sua financeirização, a lógica da fragmentação, do efêmero, do transitório, do passageiro, tudo isso restringe a plenitude e a totalidade da vida ao presente permanente, à naturalização dos processos sociais, aos facilitismos, imediatismos e aligeiramentos. Neste modelo, o melhor ensino é o mais barato, rápido e que oferece facilidades ${ }^{18}$.

Obedecendo a uma lógica mercantilista, pragmática e instrumental, a pós-graduação é instrumentalizada para responder diretamente às necessidades do capital e dos serviços oferecidos no mercado.

A análise dos Planos Nacionais de Pós-Graduação dos últimos 20 anos demonstra o aprofundamento de uma histórica política de fomento voltada a atender aos interesses da indústria brasileira, operando na direção de formar recursos humanos para o mercado, através de parcerias com empresas. Baseada em um modelo de gestão empresarial voltada às necessidades do processo produtivo, esta política de pós-graduação atual é regulamentada pela Lei de Inovação Tecnológica e complementada pela Lei do Bem. A sanção da Lei de Inovação Tecnológica ${ }^{19}$, que busca promover a inovação por meio da articulação entre os diversos setores, visa a uma maior interação universidade/empresa e a participação de pesquisadores no desenvolvimento de novas tecnologias sempre direcionadas às empresas. Esta lei prevê a participação do docente na captação de recursos no mercado oferecendo serviços de inovação tecnológica, convertendo-o em empreendedor ${ }^{20}$, mero presta-

\footnotetext{
${ }_{18}$ São espantosas as ofertas que se encontram na Internet. Dentre elas, indico o site da Rede Internacional de Ensino Livre, cuja chamada é reveladora: Acelere seu conhecimento. Trata-se de uma rede internacional que oferece ensino a distância em vários níveis. Sua missão é assim formulada: "[...] contribuir para a construção de um mundo melhor, produzindo conhecimento e formando talentos criativos e empreendedores, capazes de ter sucesso em sua vida pessoal, social e profissional". Esta rede possui uma infinidade de cursos de mestrado e doutorado com carga máxima de 1000 horas para o Mestrado e 1350 horas para o doutorado, ambos podendo ser realizados de (pasmem!) 3 a 6 meses (REDE INTERNACIONAL DE ENSINO LIVRE, [200-]).

${ }^{19}$ Esta lei (10.973/2004) de 2 de dezembro de 2004, complementada pela Lei do Bem (Lei $n^{\circ} 11.196$, de 21/11/2005) - a qual mediante a mera auto-declaração dos interessados permite a subvenção econômica e isenção fiscal às empresas que realizarem atividades de pesquisa visando a inovação tecnológica - é o exemplo típico do que é a pesquisa voltada a atender aos interesses da política industrial. Como se observa, não é casual que ela tenha plena vigência e ampla aceitação. Sobre a lei de inovação tecnológica, ver: Brasil (2004). Sobre a lei do bem: Brasil (2005).

${ }^{20}$ Cf. o artigo 14 da Lei 10.973/2004 (BRASIL, 2004), no qual é facultado ao pesquisador afastar-se
} 
dor de serviço ao mercado e/ou captador de recursos.

A vigência desta Lei explicita a política de pós-graduação perfeitamente adequada e atrelada aos interesses da política industrial brasileira (bem como aos do comercio exterior) para o que a área das ciências sociais aplicada, com sua entonação crítica a esta política, pouco tem a contribuir ${ }^{21}$.

Para Sguissardi (2009), esta lei representa a concretização do imediatismo empresarial no campo da ciência e da tecnologia, com grandes riscos para a autonomia universitária e a liberdade, produzindo um traço marcante na característica das universidades contemporâneas: a heteronomia e subsunção à política industrial e aos interesses do setor produtivo.

O Plano Nacional de Pós-Graduação (PNPG) 2011-2020 é claro quanto à estratégia para superar a defasagem do Brasil em relação a outros países no que se refere à formação pós-graduada ${ }^{22}$, através de investimentos: 1) na pós-graduação a distância; 2) nos Mestrados Profissionais (destinados à formação de recursos para as empresas) ${ }^{23}$; 3) na interdisciplinaridade; 4) em áreas estratégi-

de sua instituição, sem prejuízo do seu salário, para prestar serviços a outra Instituição Cientifica e Tecnológica.

${ }^{21}$ Otranto (2006), em seu artigo Desvendando a política da educação superior do governo LULA, identifica que os fundamentos desta contrarreforma "[...] estão calcados em marcos regulatórios defendidos pelos Organismos Internacionais. A maior parte desses fundamentos foi defendida no documento elaborado pelo Grupo de Trabalho Interministerial e direcionou medidas legais que foram sendo implantadas, desenhando a Reforma de acordo com os interesses governamentais. Dentre estas medidas, pode-se destacar o Prouni, o Sinaes, a Lei de Inovação Tecnológica, as Parcerias Público-Privadas, o Decreto que normatiza a Educação a Distância, além das medidas já adotadas para a Educação Profissional". Aqui chamo a atenção para o Mestrado Profissional.

${ }^{22}$ As duas assertivas do presidente da Capes, prof. Jorge Guimarães, são explicitas: "Para atender a defasagem atual na educação básica, o Brasil levaria 60 anos para graduar professores em Física ou 42 anos para Química" (PRESIDENTE..., 2011). "O Brasil está cerca de dez vezes abaixo de países desenvolvidos e muitos que não são desenvolvidos, mas que estão a nossa frente na questão da ciência, tecnologia e inovação" (RECOPI..., 2010).

${ }^{23}$ Através da Portaria Normativa $\mathrm{n}^{\circ} 7$, de 22 de junho de 2009, a Capes dispõe sobre o mestrado profissional (BRASIL, 2009). Esta portaria esclarece as razões do investimento. Algumas delas: “[...] a necessidade de estimular a formação de mestres profissionais habilitados para desenvolver atividades e trabalhos técnico-científicos; a necessidade de identificar potencialidades para atuação [...] em órgãos públicos, e privados, empresas, cooperativas e organizações não governamentais; necessidade de atender, particularmente nas áreas mais diretamente vinculadas ao mundo do trabalho e ao sistema produtivo, a demanda de profissionais altamente qualificados; a necessidade de capacitação e treinamento, dentre outros, tendo como objetivo capacitar profissionais qualificados para o exercício da prática profissional avançada e transformadora de procedimentos" (FORUM NACIONAL DOS MESTRADOS PROFISSIONAIS, [2011]). A flexibilização, aceleração e aligeiramento são 
$\operatorname{cas}^{24}$; 5) na internacionalização e cooperação internacional ${ }^{25}$. Tais incentivos se fazem através de política de Bolsas que privilegia os cursos de pós-graduação a distância e interdisciplinares, bem como as áreas consideradas estratégicas, evidentemente, em detrimento de outras.

Submetida a uma racionalidade produtivista, própria da universidade que se subordina aos imperativos do mercado e da moda, a nova pós-graduação brasileira como prestadora de serviços, pautada na sociabilidade que emana das relações sociais do novo imperialismo (HARVEY, 2005), cada vez mais predatórias, forma e conforma um sujeito bastante jovem e muitas vezes inexperiente ${ }^{26}$, de perfil empreendedor, que se baseia na relação custo-benefício e convencido de que o seu sucesso se deve ao seu individualismo, egoísmo, esforço isolado e à desconfiança em relação ao outro. De forma aparentemente paradoxal, também acabam por naturalizar tais critérios quantitativistas, homogêneos para todas as áreas ${ }^{27}$, geradores de competitividade, de clara influência do modelo das universidades norte-americanas. Tal homogeneização dos critérios, que ocorreu a partir de 1998 - e, segundo Horta e Moraes, se realizou, com base

claros: a Capes outorga ao seu detentor os mesmos direitos concedidos aos titulados nos Mestrados Acadêmicos; estabelece o tempo mínimo do curso de um ano e o máximo de dois anos; define que os cursos poderão ser promovidos por universidades, instituições de ensino e centros de pesquisa, públicos e privados, inclusive em forma de consórcio e flexibiliza a forma de apresentação do trabaIho final para obtenção do título de mestre, facultando a apresentação do trabalho de conclusão do curso em diferentes formatos: dissertação, revisão sistemática e aprofundada da literatura, artigo, projetos técnicos, relatório final de pesquisa, proposta de intervenção, dentre outros. Não é de se espantar se neste contexto surgirem propostas de órgãos públicos e privados no intento de formar seus próprios mestres e doutores no âmbito das novas especialidades (desprofissionalizadas) acima descritas na nota 16. É importante destacar que os Mestrados Profissionais, sendo oferecido em consórcio com as empresas e organizações públicas e privadas, possibilita à Capes dividir o ônus da sua responsabilidade de investir na pós-graduação stricto sensu.

${ }^{24}$ Segundo o (PNPG), são elas: Água, Energia, Transporte, Controle de fronteiras, Agronegócio, Amazônia, Mar, Saúde, Defesa, Justiça, Segurança Pública e Programa Espacial.

${ }^{25}$ Sobre este assunto, em reunião com coordenadores de Programas, Jorge Guimarães destacou a intenção de duplicar o número de bolsas no exterior oferecidas pela Capes. "A começar pela visita do presidente Barack Obama, que traz a proposta de duplicar a presença brasileira nos Estados Unidos a partir de assinatura de acordo", tendo como estratégia a descentralização das chamadas bolsas-sanduíche (Estágio no Exterior) (REUNIÃO..., 2011). Não é demais lembrar que esta política de mobilidade discente é parte constitutiva do protocolo de Bolonha.

${ }^{26}$ Duas exigências vêm empurrando os jovens a ingressarem cada vez mais cedo nos programas de Pós-Graduação: as exigências do mercado por qualificação (ainda que no modelo aligeirado acima indicado); a necessidade de preencher lacunas de formação deixadas pela graduação.

${ }^{27}$ Ainda que comissões de áreas tenham a prerrogativa de estabelecer seus pesos, o CTC avalia a partir de padrões comuns. 
nos critérios das ciências exatas (BIANCHETTI; SGUISSARDI, 2009) -, priva a universidade de sua especificidade, isto é, do seu sentido de universitas, como o lugar do diverso e do plural.

Sob a demanda de preencher lacunas da formação universitária e o imperativo de preencher vagas abertas pelos programas de expansão (Reuni e Prouni), resultado da massificação da educação que marca os últimos governos, muda-se o perfil do docente dos dois níveis: de graduação e de pós-graduação. O ensino e a pesquisa científica tendem a ser reduzidos: a treinamento, à transmissão de conhecimentos e ao adestramento.

Este novo perfil de pós-graduação é acompanhado do novo perfil de docentes, muitos deles incapazes de serem aprovados em concursos para publicos e/ou sem qualquer aptidão para a docência - perfil muito bem expresso por Chaui quando discute a universidade operacional:

A docência é pensada como habilitação rápida para graduados, que precisam entrar rapidamente num (novo-YADG) mercado de trabalho ${ }^{28}$ do qual serão expulsos em poucos anos, pois tornam-se, em pouco tempo, jovens obsoletos e descartáveis; ou como correia de transmissão entre pesquisadores e treino para novos pesquisadores. Transmissão e adestramento. Desapareceu, portanto, a marca essencial da docência: formação" (CHAUI, 2003, p. 7) ${ }^{29}$.

Há uma clara mudança da lógica: da formação de quadros para a docência (que nasce no modelo norte-americano, por determinação dos acordos MEC-Usaid) à formação de pesquisadores. Estes passam a ter um conjunto de novas exigências que os submetem a processos de prolongamento e intensificação do seu trabalho intelectual, causando doenças e processos de sofrimento.

\footnotetext{
${ }^{28}$ Mercado este aberto pelos planos de massificação do ensino (Reuni e Prouni). Noticias recentes indicam que até 2014 o governo espera implantar 38 novos campi universitários para os quais criará cerca de 30.100 vagas. A este respeito ver: < http://www.valor.com.br/impresso/primeirapagina/governo-retoma-grandes-contratacoes-em2010.utm_source=newsletter_manha\&utm medium $=19092011$ \&utm_term=Governo\%2oretoma\%2ograndes\%20contrata\%C3\%A $7 \%$ C $3 \%$ B 5 es\% 20 em\%202012\&utm_campaign=informativo $>$.

${ }^{29}$ Disponível em: <http://www.scielo.br/scielo.php?script=sci_arttext\&pid=S1413-24 782003000300002>. Acesso em: 4 de ago. 2011.
} 
Com este modelo de educação superior (de clara influência do Acordo de Bolonha), marcado pela ruptura entre ensino, pesquisa e extensão, tripé que o sustenta, há o aligeiramento dos cursos que agora não priorizam a pesquisa inovadora que passa a ser privilégio dos Programas de Excelência, os únicos que possuem certa autonomia para gerir seus próprios recursos ${ }^{30}$. Aos demais, reserva-se a oferta do Mestrado Profissional que titula para o mercado de trabalho e contribui com o alcance da meta do país no que se refere ao aumento do numero de titulados. Nestes, em razão da sua natureza, formato e objetivos, a pesquisa inovadora e autônoma desaparece. A educação se realiza cada vez mais conectada com a lógica do mercado, como bem de consumo imediato. Neste formato, há o interesse no aproveitamento de mestres nos setores produtivos e de doutores na pesquisa.

Quanto aos parcos recursos disponibilizados, não é qualquer pesquisa que recebe apoio financeiro: há uma clara depreciação das instituições dedicadas à pesquisa, pressionadas, a partir dos critérios de avaliação, sob critério de rentabilidade e lucro, a oferecerem soluções ao setor produtivo-mercantil submetendo seus objetivos acadêmicos aos resultados imediatos.

Como realização da já citada Lei de Inovação Tecnológica, as ciências sociais e humanas, especialmente as aplicadas, que não respondem diretamente ao mercado, são desvalorizadas31. Assim, como enuncia Maués et al, acentuou-se na universidade pública brasileira um modelo de gestão empresarial, com consequências diretas sobre o trabalho docente, com repercussão sobre a natureza das atividades desenvolvidas por esse profisional (MAUÉS; MANCEBO; CHAVES 2006). Afinal, este vem perdendo sua função crítico-formativa de formular um pensamento contestatório e autônomo.

Duas decorrências da pressão sofrida pelos pesquisadores são dignas de menção: 1) para atender as metas inatingíveis dos órgãos de fomento, estes vêm se utilizando de expediente heterodoxo para

${ }^{30} \mathrm{O}$ que significa que não ficam à mercê dos parcos recursos do Proap, os quais, cada vez mais, chegam com atraso de vários meses e submetem os programas a regras impraticáveis.

${ }^{31} \mathrm{O}$ mesmo ocorre com as ciências exatas, caso não seja aplicada, como é o caso da matemática. 
maquiar a realidade32; 2) a geração de uma nova indústria caracterizada pela compra e venda de teses e a incidência de plágio de patentes, artigos, resultado de pesquisas, dentre outros.

A avaliação tem sido um capítulo a parte. Muita tinta tem sido gasta sobre a questão da Avaliação da Pós-Graduação. O que figura neste meio é um duelo que parece polarizar os que são a favor e os que são contra avaliar. Mas esta aparente oposição não alcançar a questão de fundo: de que modelo de avaliação se trata? Sob que parâmetros tal avaliação será realizada?

Nesta direção, temos que nos perguntar qual modelo de avaliação que acaba sendo naturalizado entre nós. Qualquer maneira de avaliação vale a pena? Em que consiste o modelo de avaliação da Capes? Avaliar o que, por que e sob quais critérios? É possível avaliar áreas diferentes com os mesmos parâmetros e critérios de relevância social?

Estudiosos sobre o tema vêm apontando que o modelo Capes de avaliação padece de alguns problemas de concepção. A Capes é uma agência reguladora e enquanto tal tem como função a fiscalização da legislação existente. Nesta direção, Sguissardi (2009) pergunta: "[...] é possível conciliar avaliação educativa com processo de regulação e controle do Estado?" Argumentando que a formulação do modelo Capes aparece nos anos de 1996/1997, no mesmo momento em que se estabelece o Exame Nacional de Cursos, conhecido como Provão, o estudioso pergunta:

Que conseqüência traz para a educação superior o fato de se adotar um modelo de avaliação que privilegia a formação do pesquisador, via mensuração e avaliação bastante quantitativista da produção cientifica, em detrimento da formação integral do pós-graduando? (SGUISSARDI, 2009, p. 135).

Sguissardi (2009, p.137-141) critica a identificação entre padrão de regulação com avaliação como medida de controle, no contrapon-

${ }^{32}$ Têm-se informações de que os pesquisadores vêm cedendo às investidas de algumas revistas científicas com Qualis A1 que exigem pagamento de taxa para a publicação de artigos. Programas revalidam disciplinas de estudantes ouvintes visando mascarar os prazos de titulação. 
to do que o autor chama de avaliação educativa ou diagnóstico-formativa. Concebe que avaliação não pode se constituir em forma de controle, punição ou premiação. Constata-se que ao tomar como critérios a produção quantitativa não se prioriza a formação de mestres e doutores, mas o número de titulados. É a lógica dos quantos entram e quantos saem, números estes que matrizam os recursos destinados à pós. Isso incide numa baixa qualificação de mestres e doutores que nem sempre têm habilidade e competência para tal, já que a pós-graduação vem gradualmente perdendo sua função política e formativa, seu papel na construção de um pensamento contestatório e autônomo.

O modelo Capes impõe uma avaliação que se faz abstraída da análise crítica do contexto educacional, bem como das condições em que certas exigências são cumpridas: a busca pela suposta excelência se dá num contexto de brutal precarização das relações e condições de trabalho, causando o adoecimento profissional; a suposta produtividade se reduz ao produtivismo e este se configura como um fordismo intelectual, "em um tempo de que a pesquisa encontra-se administrada” (WARDE apud BIANCHETTI; MACHADO NETO, 2006). Ora, é absolutamente paradoxal, incompatível ou mesmo hipócrita querer buscar a excelência ao tempo em que se impõe uma brutal precarização das condições e relações de trabalho.

Como assevera Chaui (2001, p.184),

[...] os critérios da produtividade são quantidade, tempo e custo, que definirão os contratos de gestão. Observa-se que a pergunta pela produtividade não indaga: o que se produz, como se produz, para que ou para quem se produz, mas opera uma inversão tipicamente ideológica da qualidade em quantidade. Observa-se também que a docência não entra na medida da produtividade (CHAUI, 2001, p.184).

Ora, o modelo Capes de avaliação, estabelece métodos, médias e medianas aparentemente neutros e válidos para todas as áreas. $\mathrm{Na}$ medida em que não dá conta das particularidades de cada área, sua natureza, dinâmica da pesquisa, diferenças entre seus processos e produtos e o impacto social punem os que não alcançam a meta 
instituída, que não casualmente atende aos critérios das ciências duras, desqualificando áreas e pesquisadores que são rotulados de inaptos ou incompetentes.

A avaliação precisa ser situada dentro de seus limites. Ela vale o que vale. Ela não é mais do que uma avaliação realizada por uma agência de regulação que tem como orientação a indução da produção, o que significa imprimir nesta avaliação uma lógica competitiva e hierárquica, dentro de critérios que fogem à natureza e à lógica da produção das ciências sociais e, mais ainda, das ciências sociais aplicadas. Além das diferenças em termos de áreas, há que se mencionar as diferenças regionais.

Ora, tem sido objeto de crítica o fato de que tais critérios não levam em conta as diferenças regionais, em termos de temas e possibilidades de divulgação da produção. Há que se considerar que muitas vezes os temas mais importantes do ponto de vista local ou nacional não são de interesse de veiculação de revistas Qualis A1, exatamente pelo seu perfil internacional.

Dentro desta lógica, não se leva em conta a relação entre redução dos prazos e qualidade. Ainda que se considere que não haja uma relação direta entre elas, para se ter qualidade há que se ter prazos razoáveis. Impossível ter boa produção se não se tem tempo de amadurecimento intelectual, decantação do conhecimento. $O$ conhecimento dever ser digerido - com tudo o que esta palavra significa.

Este modelo é por nós não apenas aceito, mas naturalizado, numa total passividade, já que não vislumbramos qualquer alternativa a ele. Muitas de suas exigências nos servem muito pouco. Caso, por exemplo, nossas produções fossem publicadas apenas em veículos internacionais, a pesquisa e a produção se distanciariam cada vez mais das necessidades e interesses da sociedade brasileira, e, sobretudo, das classes populares. A universidade acabaria reforçando seu caráter elitista e antipopular. 


\section{“NÓS” DA PÓS: O SERVIÇO SOCIAL EM CENA}

Apesar do acúmulo de potencialidades resultante destas breves três décadas de implantação da pós-graduação stricto sensu em Serviço Social no Brasil, nas quais a área logrou construir um espaço que se encontra em franco crescimento e detém vitalidade e enormes possibilidades, dadas especialmente pelo seu caráter interdisciplinar e sua perspectiva crítica33, os reflexos deste modelo reverberam na área em vários aspectos.

A seguir, faremos alguns apontamentos a partir de uma visão panorâmica da área, baseada em algumas observações empíricas e análises factuais e em dados dos relatórios elaborados pela Comissão Técnica da área na Capes.

Ao contrário da tendência mais geral, e na direção da nossa cultura profissional com fraca tradição em pesquisa, o enfoque da nossa pós-graduação está no ensino. Os programas de Pós-Graduação da área mantêm uma importante função de formação de quadros para a docência tanto para o Brasil quanto para outros países do continente latino-americano (Argentina, Uruguai, Chile, Costa Rica, Colômbia, Venezuela) e europeu, especialmente, Portugal. Com menor incidência, também intervém na formação de docentes e profissionais que atuam no continente africano (Cabo Verde, Angola e Moçambique). Vêm também formando a massa crítica inserida na formulação e implementação de políticas sociais, nos conselhos de direitos, nas organizações não governamentais e, ainda que em menor incidência, nos movimentos sociais. Os Programas encontram-se bem estruturados com disciplinas apresentando conteúdos e bibliografia atuais e em conexão com as áreas de concentração e linhas de pesquisa. Ressalta-se que a procura pelos nossos Programas extrapola a área de Serviço Social: muitos dos candidatos que os procuram são de áreas afins e estão interessados num debate critico que se faz em torno do capitalismo contemporâneo e suas formas de enfrentar a chamada questão social.

33 Crescimento marcado pelo aumento de 10 cursos em menos de 6 anos e com a ascensão de nível de 7 Programas. Ressalta-se que entre 2000 e 2009 a área implantou 15 cursos de Pós-Graduação. 
Já foi mencionado o avanço da pesquisa quando foi reconhecida e instituída a partir da mudança do estatuto da entidade em 1998, através da lúcida decisão da categoria em integrar Abess e Cedepss, instaurando e mantendo a necessária transversalidade entre graduação e pós-graduação, bem como garantindo suas duas dimensões: como subsídio ao exercício profissional e como produtora de conhecimento.

Não obstante aos avanços, a apreciação da produção científica em desenvolvimento mostra fragilidade na formação de pesquisadores. Para exercitar as duas dimensões da pesquisa no Serviço Social (como mediação da pratica e como produção do conhecimento) é necessário claro investimento e um rigoroso preparo teórico-metodológico ${ }^{34}$. A este respeito cabe a seguinte observação: o que é a nossa linha de força pode se tornar uma fraqueza, ou seja, nossa pesquisa, quando referida a situações do exercício profissional não passa de sistematização da prática, limitando ao seu aspecto descritivo; a pesquisa na área tem um reconhecido crescimento quantitativo, mas não vem sendo qualificada na mesma medida de seu crescimento.

Iamamoto (2010) identifica, ainda, certa fragilidade no tratamento dos fundamentos históricos e teórico-metodológicos do Serviço Social. Indica a necessidade de aprofundar o conhecimento crítico sobre: o Serviço Social clássico, o movimento de reconceituação latino-americano, suas particularidades e tendências, o Serviço Social internacional e o Serviço Social na contemporaneidade, suas demandas e o processamento de seu trabalho ${ }^{35}$.

A meu ver, temos a necessidade de enfrentar a concepção instrumental de ciência e a tendência de valorizar apenas o conhecimento instrumental, voltado a solucionar problemas numa perspectiva da racionalidade própria de profissões interventivas.

Sofremos ainda do isolamento das investigações, na medida em que o predomínio é da produção individual, fruto de monografias, teses e/ou dissertações.

34 Já que muitas vezes a pesquisa é reduzida a mero diagnóstico de situações da intervenção profissional ou método de intervenção, limitadas que são às técnicas de pesquisa-ação e/ou grupos focais.

${ }^{35}$ Palestra pronunciada no Colóquio do GTP de Fundamentos do Serviço Social: Trabalho e Formação Profissional no Encontro Nacional de Pesquisadores em Serviço Social (Enpess), em dezembro de 2010. 
É neste aspecto que entendemos que a estratégia dos GTPs, desenvolvida pelas duas últimas gestões de Abepss (2009-2010 e 2011-2012), vem na direção do fortalecimento da pesquisa na área, rompendo com o isolamento, com a lógica da pesquisa individual, com a autonomização e pulverização do conhecimento e na direção de fornecer subsídios para a elaboração de uma política de pesquisa, já indicada há décadas, como um dos desafios da entidade. Há o pioneirismo da iniciativa da formação da primeira Rede de Pesquisa na área e um avanço no fato de que a mesma se aglutine em torno do trabalho profissional ${ }^{36}$. Ao mesmo tempo, nota-se o crescimento dos Núcleos e Grupos de Pesquisas e da liderança cada vez maior de pesquisadores da área na consolidação destes Grupos que vêm contando com a participação de discentes da graduação e da pós, mas também de assistentes sociais.

Há que se enfatizar que a vitalidade da área está na sua ampla produção técnica e grande inserção social dos programas - e mesmo os menos consolidados portam a tendência de desenvolver projetos de pesquisa e extensão de relevância social e sua produção técnica repercute em diferentes espaços sócio-ocupacionais e áreas de conhecimentos.

A produção crítica do Serviço Social brasileiro vem atravessando o continente latino-americano, especialmente, mas não exclusivamente, através da Biblioteca Latino-Americana publicada pela Editora Cortez.

Destaca-se o crescimento numérico dos Programas nos dois últimos triênios (2004-2006) e (2007-2009). Tal crescimento também vulnerabiliza a área que passa a ter como desafio a consolidação de cursos novos, à luz de critérios idênticos aos das ciências exatas e naturais e os mesmo dos Programas já consolidados. No último triênio, também se destaca a quebra da imobilidade dos Programas. Por muitos anos, alguns programas de referência para a área e para áreas afins tiveram suas notas mantidas, sem possibilidade de alteração. No último triênio, esta imobilidade foi

${ }^{36}$ Trata-se da Retas, iniciativa a ser reproduzida por outras áreas temáticas, que vêm articulando os Grupos e Núcleos de Pesquisa em torno das condições e relações de trabalho do assistente social. 
quebrada, resultando reclassificação de sete Programas ${ }^{37}$.

A área ainda se ressente de uma cultura de cooperação e intercâmbio, embora nos dois últimos triênios isso tenha avançado muito em termos de nossa participação nos programas como Dinter, Minter, Casadinho, Procad, em nível nacional e de alguns convênios e intercâmbios internacionais.

Apesar da tendência de ampliar os projetos de cooperação e intercâmbio, como um movimento mais geral da lógica da pós-graduação, vive-se num ambiente de competitividade entre áreas, programas, docentes e pesquisadores, o que vem nos tornando cada vez mais segmentados, individualizados e fragilizados ${ }^{38}$.

A qualificação de periódicos e revistas cientificas da área, no sentido da sua indexação em bases nacionais e internacionais, tem sido forte e corajosamente encaminhada pelos seus editores. Esforços coletivos por parte da diretoria e de pesquisadores vêm sendo feitos para elevar o Qualis da Revista Temporalis. Não obstante a estes esforços, nossa produção padece de questionamento, tais como: qual é a produção do Serviço Social, qual a sua abrangência?

\section{CONSIDERAÇÕES FINAIS: NENHUMA PRODUÇÃO PODE SER OBJETO DE CIENTOMETRIA}

Segundo a material do Informativo Fapesp,

Dados divulgados pelo governo do Brasil no ano de 2009 demonstram, entre os anos de 2002 e 2008, um aumento de $205 \%$, no número de periódicos científicos indexados na base de dados internacional Web of Science-ISI (WoS) (CASTRO, 2009)".

37 São eles: UERJ, UFRJ, UFES, UFMA, PUC-RS, UCSAL e UCPEL.

${ }^{38}$ llustrativo do desgaste pessoal e em termos de relações pessoais e sociais é o vídeo publicado no YouTube: Vida Pós-Graduação. 
É certo que não é este crescimento que interessa à sociedade brasileira nem é exatamente isso que expressa um reconhecimento da produção intelectual do Brasil. É certo que precisamos questionar os critérios que avaliam a produção no país.

Neste sentido, como grande desafio para a Pós-Graduação na área e que requererá grande investimento das entidades, dos nossos representantes nas agências de fomentos, dos coordenadores de programas, docentes e discentes, podemos indicar a necessidade de um amplo e sistemático debate: qual é o modelo de Pós-Graduação que nos cabe construir? Igualmente importante é questionar quais são indicadores de qualidade da nossa produção, considerando não só as suas características, mas também os valores e princípios do nosso projeto ético-político, e aqui cabe ainda uma observação: em face destes valores, devemos vislumbrar um modelo de Pós-Graduação que muito diverge do modelo atual.

Nele, privilegiar-se-ia a formação de um sujeito que pudesse indagar-se sobre a realidade em que vive e que não aceitasse passivamente a mercantilização, o aligeiramento e a banalização da formação profissional. Priorizar-se-ia a produção que tem relevância social, ou seja, que responda às necessidades e interesses da sociedade, que esteja a serviço da classe trabalhadora, dos movimentos sociais e de suas lutas.

Daríamos prioridade, ainda, às iniciativas que contemplassem a solidariedade entre os programas, na direção de alavancar aqueles que se encontrassem mais fragilizados diante desta lógica, o mesmo ocorrendo em relação às Revistas do Programas de Pós-Graduação, desenvolvendo iniciativas de colaboracionismo.

A avaliação que nos contemplaria seria a que mede o impacto que as atividades desenvolvidas pelos Programas têm no âmbito acadêmico e na sociedade. A avaliação seria um processo coletivo que envolveria todos os sujeitos que vêm protagonizando a construção da Pós-Graduação e cada um, segundo a sua forma de inserção, participaria do processo no intuito de qualificá-la. Nela, haveria espaço para a participação dos sujeitos (discentes e docentes) sobre a qualidade das atividades que desenvolvem, sobre os parâmetros 
de avaliação acerca destas atividades, dentre eles a qualidade das teses e dissertações, dando especial relevo às que fossem indicadas para publicação ${ }^{39}$.

Priorizar-se-ia a produção de conhecimento que revelasse as novas expressões da velha questão social e desvelasse o seu fundamento, o qual nos permitiria fazer a crítica da sociedade burguesa e do padrão de política social vigente.

No âmbito das pesquisas, seriam valorizados indicadores de medida do impacto social do conhecimento produzido nos cursos de pós-graduação e a sua função social. Perguntar-se-ia, portanto, qual é a relevância das nossas pesquisas; como elas estão conectadas com os interesses da sociedade. Como temos veiculado e socializado nossa produção no sentido de dar a ela visibilidade junto aos sujeitos sociais individuais e coletivos com os quais trabalhamos, muitas vezes sujeitos das próprias investigações que realizamos.

Como medida da nossa internacionalização, tomaríamos a interlocução privilegiada que estabelecemos com o Serviço Social latino-americano na construção de um Serviço Social Crítico, estreitando com os países desse território relações cooperativas. Manteríamos as táticas e estratégias de enfrentamento das tendências de aligeiramento do conhecimento, dentre elas a do Mestrado Profissional, demanda que tem sido colocada pela Capes para a área desde os anos 2000, e à época corajosamente enfrentada pelos programas por considerarem que a mesma, além de favorecer a mercantilização do ensino no âmbito da pós-graduação, empobrece e fragiliza a área diante das demais e tende a extinguir os cursos de mestrado acadêmico.

Uma questão que me parece fundamental é sobre o caráter do conhecimento que produzimos. Não estaríamos desqualificando o caráter aplicativo do conhecimento produzido pelo Serviço Social na formulação, gestão, implementação e avaliação das políticas sociais e no enfrentamento do binômio crescimento-desigualdade

${ }^{39}$ Ainda que nunca sejam publicadas realmente, pois as editoras comerciais estão sempre preocupadas em lançar livros de autores já conhecidos. 
social? Temos a clara percepção da sua importância? Temos informação sobre como ele está sendo utilizado, quem são os sujeitos que o utilizam e como o fazem?

Ora, no modelo de pós-graduação que queremos, a avaliação tem que incorporar indicadores sociais relevantes para a sociedade; deve reivindicar a criação de canais de participação efetiva dos docentes e discentes, pesquisadores, profissionais e sociedade na discussão e formulação da política de pesquisa e pós-graduação para o país.

Este modelo requer resgatar o papel social e crítico da universidade brasileira, como instituição social, efetivamente pública, gratuita, democrática, autônoma, socialmente referenciada, dotada de recursos materiais e humanos capazes de atender às demandas do desenvolvimento do ensino, da pesquisa e da extensão, onde a educação é pensada como um direito e não como um serviço concebido e avaliado sob critérios mercantis.

Este modelo tem que estar sintonizado com os valores do projeto profissional construído pela profissão na luta contra o histórico conservadorismo que marca a sua trajetória, servindo aos segmentos da população que buscam as políticas sociais como única forma de atendimento das suas necessidades de sobrevivência.

Ele requisita uma clara definição sobre a política de financiamento que priorize as pesquisas socialmente relevantes e uma educação que esteja a serviço da construção de uma sociedade que lute contra as desigualdades de classe, raça, credo, etnia, religião, gênero, dentre outras.

Por este modelo, nos últimos 30 anos, a Abepss vem lutando incansavelmente, participando das lutas mais gerais da sociedade, a exemplo da defesa dos 10\% do PIB para a Educação, fecundando estratégias - a exemplo da PNE, GTPs, Abepss Itinerante - e organizando trincheiras na perspectiva da defesa da formação profissional (graduada e pós-graduada) de qualidade como uma das mediações necessárias a uma construção da nova sociedade. 


\section{REFERÊNCIAS}

ABEPSS. Diretrizes Curriculares da ABEPSS 1996. 1996. Disponível em: <http://www.abepss.org.br/briefing/graduacao/Lei_de_Diretrizes_Curriculares_1996.pdf>. Acesso em: 15 ago. 2010.

ABEPSS. Apresentação. Temporalis: Revista da Associação Brasileira de Ensino e Pesquisa em Serviço Social, Brasília, n. 1, ano 1, 2000.

BIANCHETTI, Lucídio; SGUISSARDI, Valdemar (Org.). Dilemas da Pós-Graduação: gestão e avaliação. São Paulo: Autores associados, 2009.

BIANCHETTI, Lucídio; MACHADO, Ana Maria N. A bússola do escrever: desafios e estratégias na orientação e escrita de teses e dissertações. 2. ed. São Paulo: Cortez, 2006.

BRASIL. Lei $n^{\circ} 10.973$, de 2 de dezembro de 2004. Dispõe sobre incentivos à inovação e à pesquisa científica e tecnológica no ambiente produtivo e dá outras providências. 2004. Acesso em: <http:// www.planalto.gov.br/ccivil_03/_Ato2004-2006/2004/Lei/L10.973. htm>. Acesso em: 30 ago. 2010.

BRASIL. Lei n¹1.196, de 21 de novembro de 2005. Institui o Regime Especial de Tributação para a Plataforma de Exportação de Serviços de Tecnologia da Informação - REPES, o Regime Especial de Aquisição de Bens de Capital para Empresas Exportadoras - RECAP e o Programa de Inclusão Digital; dispõe sobre incentivos fiscais para a inovação tecnológica; altera o Decreto-Lei no 288 , de 28 de fevereiro de 1967, o Decreto no 70.235 , de 6 de março de 1972, o Decreto-Lei $\mathrm{n}^{\circ} \mathbf{2 . 2 8 7}$, de 23 de julho de 1986 , as Leis $\mathrm{n}^{\mathrm{os}} 4.502$, de 30 de novembro de 1964, 8.212, de 24 de julho de 1991, 8.245, de 18 de outubro de 1991, 8.387, de 30 de dezembro de 1991, 8.666, de 21 de junho de 1993, 8.981, de 20 de janeiro de 1995, 8.987, de 13 de fevereiro de 1995, 8.989, de 24 de fevereiro de 1995, 9.249, de 26 de dezembro de 1995, 9.250, de 26 de dezembro de 1995, 9.311, de 24 de outubro de 1996, 9.317, de 5 de dezembro de 1996, 9.430, de 27 de dezembro de 1996, 9.718, de 27 de novembro de 1998, 10.336, de 19 de dezembro de 2001, 10.438, de 26 de abril de 2002, 
10.485, de 3 de julho de 2002, 10.637, de 30 de dezembro de 2002, 10.755 , de 3 de novembro de 2003, 10.833, de 29 de dezembro de 2003, 10.865, de 30 de abril de 2004, 10.925, de 23 de julho de 2004, 10.931, de 2 de agosto de 2004, 11.033, de 21 de dezembro de 2004, 11.051, de 29 de dezembro de 2004, 11.053, de 29 de dezembro de 2004, 11.101, de 9 de fevereiro de 2005, 11.128, de 28 de junho de 2005, e a Medida Provisória no 2.199-14, de 24 de agosto de 2001; revoga a Lei no 8.661, de 2 de junho de 1993, e dispositivos das Leis n⿳⺈⿴囗十 8.668 , de 25 de junho de 1993, 8.981, de 20 de janeiro de 1995, 10.637, de 30 de dezembro de 2002, 10.755, de 3 de novembro de 2003, 10.865, de 30 de abril de 2004, 10.931, de 2 de agosto de 2004, e da Medida Provisória no 2.158-35, de 24 de agosto de 2001; e dá outras providências. Disponível em:<http://www.planalto.gov.br/ ccivil_03/_ato2004-2006/2005/lei/l11196.htm>. Acesso em: 1 ago. 2011.

BRASIL. Ministério da Educação. Portaria $n^{\circ} 7$, de 23 de junho de 2009. Dispõe sobre o mestrado profissional no âmbito da Fundação Coordenação de Aperfeiçoamento de Pessoal de Nível Superior - Capes. Diário Oficial [da] República Federativa do Brasil, Brasília, n.117, 23 jun. 2009. Seção 1, p.31-32. Disponível em: <http://www. capes.gov.br/images/stories/download/legislacao/Revogada-Portaria-Normativa-n_7-22-de-junho-2009-Mestrado-Profissional.pdf >.

CARVALHO, Denise B. B.; SILVA SILVA, Maria O. (Org.). Serviço Social, Pós-Graduação e Produção de conhecimento no Brasil. São Paulo: Cortez, 2005.

CASTRO, Fábio. Questão de qualidade. Agência FAPESP, São Paulo, 14 maio 2009. Disponível em: <http://www.agencia.fapesp.br/materia/10488/questao-de-qualidade.htm>.

CENTRO DE DOCUMENTAÇÃO E PESQUISA EM POLÍTICA SOCIAL E SERVIÇO SOCIAL. Configuração de um projeto profissional para o Serviço Social: o pensamento das entidades nacionais. Local?: Abess-Cedepss, 1994. (Cadernos de Pesquisa Cedepss, n. 1.)

CENTRO DE DOCUMENTAÇÃO E PESQUISA EM POLÍTICA SOCIAL E SERVIÇO SOCIAL. Estudo de 10 anos da Revista Serviço Social e 
Sociedade (1979-1989). Abess-Cedepss, ago. 1994. (Cadernos de Pesquisa Cedepss, n. 2)

CHAUÍ, Marilena. Reforma do ensino superior e autonomia universitária. Revista Serviço Social \& Sociedade, São Paulo, ano 20, 1999.

- A universidade pública sob nova perspectiva. In: REUNIÃO ANUAL DA ANPED, 26., 5 out. 2003, Poços de Caldas (MG). Conferência de abertura. Disponível em: <http://www.artnet.com. br/ apesjf/unipub.html>. Acesso em: 11 maio 2010.

. Escritos sobre a universidade. São Paulo: Ed. Unesp, 2001.

DANTAS, Flavio. Responsabilidade social e pós-graduação no Brasil: idéias para (avali)ação. R B P G, local?, v. 1, n. 2, p. 141-159, nov. 2004. Disponível em: <http://www2.capes.gov.br/rbpg/images/stories/downloads/RBPG/Vol.1_2_nov2004_/160_172_responsabilidadesocial_posgraduacao_brasil.pdf $>$.

EDITORIAL. Cadernos Abess, n. 8, 1998.

ENDERLE, Rubens. Apresentação. In: MARX, K. Critica da filosofia do direito de Hegel. São Paulo: Boitempo, 2006.

FÓRUM NACIONAL DOS MESTRADOS PROFISSIONAIS. Documentos para leitura. [2011]. Disponível em: <http://www.fnmp.org.br/ documentos/>. Acesso em: 4 maio 2010.

GUERRA, Yolanda. A formação profissional frente aos desafios da intervenção e das atuais configurações do ensino publico, privado e a distância. Revista Serviço Social e Sociedade, São Paulo, 2011.

HARVEY, David. O novo imperialismo. São Paulo: Loyola, 2005.

HORTA, José S. B.; MORAES, Maira Celia M. O sistema Capes de pós-graduação: da área de educação à grande área de Ciências Humanas. In: BIANCHETTI, Lucídio; SGUISSARDI, Valdemar (Org). Dilemas da pós-graduação: gestão e avaliação. São Paulo: Autores associados, 2009.

IAMAMOTO, Marilda V. Serviço Social em tempo de capital feti- 
che: capital financeiro, trabalho e questão social. São Paulo: Cortez, 2008.

. O debate contemporâneo do Serviço Social e a Ética profissional. In: BONETTI, D. et al. (Org.). Serviço Social e ética: convite a uma nova práxis. São Paulo: Cortez-CFESS, 1996.

. A Renovação e conservadorismo no Serviço Social: ensaios críticos. São Paulo: Cortez, 1992.

LIMA, Leila. Una parte de la historia del Trabajo Social: 6 años en el CELATS. [1984]. Disponível em: <http://www.ts.ucr.ac.cr/binarios/ pela/pl-000131.pdf >. Acesso em: abr. 2010.

MAUÉS, Olgaíses; MANCEBO, Deise; CHAVES, Vera Jacob. Crise e reforma do Estado e da Universidade Pública: implicações para o trabalho docente. Educar em Revista, Curitiba, n. 28, p. 37-53, 2006.

NETTO, José Paulo. Ditadura e Serviço Social: uma análise do Serviço Social no Brasil pós-64. São Paulo: Cortez, 1990.

. A reconceituação: ainda viva, 40 anos depois. In: ALAYÓN, N. (Org.). Trabajo Social Latinoamericano: a 40 años de la reconceptualización. Buenos Aires: Espacio, 2005.

- Transformações societárias e Serviço Social: notas para uma análise prospectiva da profissão. Revista Serviço Social e Sociedade, São Paulo, ano 17, n. 50, abr. 1996.

OTRANTO, Celia R. Desvendando a política da educação superior do governo Lula. Revista Universidade e Sociedade do Andes-SN, ano 16, n. 38, p. 18-29, jun. 2006. Disponível em: http://www.celia. na-web.net/pasta1/trabalho14.htm. Acesso em: 10 maio 2010.

PONTIFÍCIA UNIVERSIDADE CATÓLICA DO RIO DE JANEIRO. Programa de Pós-Graduação em Serviço Social. @1992-2011. Disponível em: <http://www.puc-rio.br/ensinopesq/ccpg/progser. html\#apresentacao >. Acesso em: 2 set. 2011.

PRESIDENTE da Capes apresenta desafios desta década para a 
pós-graduação. 3 mar. 2011. Disponível em: <http://www.ufjf.br/ secom/2011/03/03/presidente-da-capes-apresenta-desafios-desta-decada-para-a-pos-graduacao/>).

RECOPI homenageia os dez anos da área interdisciplinar. $1 \mathrm{dez}$. 2010. Disponível em: <http://www.capes.gov.br/servicos/sala-de-imprensa/36-noticias/4258-recopi-homenageia-os-dez-anos-da-aerea-interdisciplinar>). Acesso em: 1 mar. 2011.

REDE INTERNACIONAL CURSOS DE ENSINO LIVRE. [200-?]. Disponível em: http://www.redeinternacional.com.br/?sec=a_rede). Acesso em: 25 de ago. 2011.

REUNIÃO do Proex recebe 220 coordenadores de programas de pós-graduação. 21 mar. 2011. Disponível em: <http://www.capes. gov.br/servicos/sala-de-imprensa/36-noticias/4459-reuniao-do-proex-recebe-220-coordenadores-de-programas-de-pos-graduacao >. Acesso em: mar. 2011.

REVISTA MUNDO CORPORATIVO. A educação por um país mais competitivo. Disponível em: <http://noite.wordpress.com/2010/05/09/ aprender-a-educacao-por-um-pais-mais- competitivo>. Acesso em: 25 ago. 2010.

SGUISSARDI, Valdemar; SILVA JÚNIOR, João dos R. 0 trabalho intensificado nas federais: pós-graduação e produtivismo acadêmico. São Paulo: Xamã, 2009.

SGUISSARDI, Valdemar. A avaliação defensiva no Modelo Capes de Avaliação: é possível conciliar avaliação educativa com processos de regulação e controle do Estado? In: BIANCHETTI, L.; SGUISSARDI, V. (Org.). Dilemas da Pós-Graduação: gestão e avaliação. São Paulo: Autores associados, 2009.

SILVA, Maria Ozanira Silva(Org.). O pensamento das entidades nacionais.Cadernos de Pesquisa Cedepss, n.1, ago.1994.

SILVA, Maria Ozanira Silva(Org.). Estudo de 10 anos da Revista Serviço Social e Sociedade (1979-1989).Cadernos de Pesquisa Cedepss, n.1, ago.1994. 
SILVA JÚNIOR, José dos Reis. Tendências do ensino superior diante da atual reestruturação do processo produtivo no Brasil. In: CATA$\mathrm{NI}, \mathrm{A}$. (Org.). A universidade na América Latina: tendências e perspectivas. São Paulo: Cortez, 1996. p. 11-33.

SINDICATO NACIONAL DOS DOCENTES DAS INSTITUIÇÕES DE ENSINO SUPERIOR. Educação a distância, abertura do mercado educacional ao capital estrangeiro e ampliação espúria da educação superior: uma crítica à política de EAD do governo Lula da Silva. 2005. Disponível em: <http://www.andes.org.br/imprensa/arquivo/ default_reforma_universitaria.asp>. Acesso em: 10 ago. 2010.

SPAGNOLO, Fernando; SOUZA, Valdinei C. O que mudar na avaliação da Capes? Revista Brasileira de Pós-Graduação, local? v. 1, n. 2, p. 8-34, nov. 2004. Disponível em: <http://www2.capes.gov.br/rbpg/ images/stories/downloads/RBPG/Vol.1_2_nov2004_/08_34_o que_mudar_na_avaliacao_capes.pdf>. Acesso em: ago. 2011.

VALOR ECONÔMICO. Disponível em: <http://www.valor.com.br/ impresso/primeira-pagina/governo-retoma-grandes-contratacoes-em-2010>. Acesso em: 19 set. 2011. 